\section{The determination of trait redundancy in personality impression formation*}

\author{
MARTIN F. KAPLAN \\ Northern Illinois University, DeKalb, Ill. 60115
}

Redundancy, or interrelatedness of traits, was determined either by having Ss select traits from a master list which were implied by a given trait or by having them rate the likelihood of one trait implying another. Methods yielded comparable results. Consistent with expectations, redundancy was found to attenuate the set-size effect in impression formation. Increases in response polarity, with increased number of descriptive traits, were greater in sets of nonredundant, as compared to redundant, traits.

Several authors have pointed out that there exist learned associations or interrelations between traits, so that a given trait may readily imply several other traits (cf. Bruner et al, 1958; Cronbach, 1955; Hays, 1958; Koltuv, 1962; Osgood et al, 1957). For example, if a person is intelligent, he is likely to be interesting, but not necessarily honest. Thus, in forming impressions of others, we have expectancies of certain traits going together. These expectancies have been variously labeled as "halo effect" (Thorndike, 1920), "logical error" (Newcomb, 1931), "implicit personality theory" (Cronbach, 1955), "trait inference" (Bruner et al, 1958), and "trait implications" (Hays, 1958). Recent factorial studies (Hakel, 1969; Passini \& Norman, 1966) have confirmed the stability of these intercorrelations across both $S s$ and levels of $S$ familiarity with the stimulus person.

The degree of trait implication has special relevance for impression formation. Typically, Ss are presented a number of adjectival traits ascribed to a stimulus person and are asked to report their impression of him, often in terms of a likableness rating. Clearly, to the extent that words within a given trait set imply one another, i.e., are redundant, the information contained in the set is diminished. Although rarely treated as an independent variable, degree of redundancy is likely an important factor in the combination of the stimulus items into a unitary impression, particularly in light of the facts that sets are often formed of traits of similar evaluation and that redundancy is maximized when evaluative level of traits is uniform (Halverson, 1970).

* A preliminary version of this paper was read at the Meetings of the Midwestern Psychological Association, Cincinnati, 1970. The theoretical comments of Norman $H$. Anderson are appreciated.
One impression formation phenomenon in which the effect of redundancy has been investigated is the set size effect. The set size effect refers to the frequent finding that increasing the number of traits in a set with evaluative level of traits constant leads to a more extreme evaluation of the composite. It would be reasonable to expect that this effect would be attenuated to the degree that traits within sets are redundant. Thus, the addition of the trait honest to sincere would be less likely to increase your liking for Person A than would the addition of generous.

Several studies have confirmed the expected interaction between redundancy and set size (Chalmers, 1964; Dustin \& Baldwin, 1966; Schmidt, 1969), while Radtke (1967) found set size attenuated only when redundancy was increased by repetition of traits. A major problem in the experimental definition of redundancy, however, has limited generalizability of results. Previous studies have manipulated redundancy either by selecting similarly prerated synonyms for redundant, and semantically unrelated, traits for nonredundant sets or by simple repetition of traits, resulting in a lack of uniformity of definition. The former method unfortunately requires subjective judgment by the $E$, and the latter, while investigating an interesting variable in its own right, does not address the question of trait implication.

It would be preferable to employ empirically determined pragmatic redundancy in constituting redundancy levels. The purpose of this study was twofold: (1) to determine if redundancy, defined by Ss' judgments of trait implications, attenuates the set size effect; and (2) to determine empirical redundancy (trait implications) of traits commonly employed in impression formation via two methods.
DETERMINATION OF REDUNDANCY

Matching Procedure

Two lists of trait words were assembled, drawing upon Anderson' (1968) normative ratings. One list contained $\mathbf{4 0}$ traits normatively rated as highly likable $(\mathrm{H})$ and the other list contained 45 highly dislikable (L) traits. Within each list, 43 Ss selected the five traits "most nearly implied" by each trait in turn. Thus, for each $S$, there was obtained for each trait five other traits of similar likability which were most nearly implied by that trait. Responses to each trait were then pooled across Ss, and, for a given trait, another trait was considered redundant if selected by $2 \Omega$ or more Ss. Conversely, trait pairs in which no implication choices were obtained from one trait to the other were considered nonredundant. ${ }^{1}$

\section{Rating Procedure}

Following Hays (1958), an independert sample of Ss rated, from "impossible" (1) to "certain" (7), the likelihood that a person possessing a given trait would also possess each of the remaining traits in the appropriate list $(\mathrm{H}$ or $\mathrm{L})$. Specifically, Ss were given $15 \mathrm{H}$ (or $L$ ) traits and were asked to rate, for each, the degree of implication for the remaining 39 (or 44) traits at the same likability level. The following serves as an example of the task:

(A) Suppose a person is annoying. How likely is it that he is also:

(1) belligerent

(2) boring

(3) conceited

.

(44) vulgar

Due to the length of the rating task, each of six $S$ groups rated from 10 to 15 traits against the master lists. Ns ranged from 32 to 54 .

PERSON IMPRESSION RATINGS

Students in an introductory psychology course rated likableness of 280 trait words which sampled the range of likableness in Anderson's (1968) norms. Traits were employed in impression ratings only if $\mathbf{S}$ assigned a rating of 5-6 (or 0-1) on a 7-point likableness scale (0-6) and they were designated as $\mathrm{H}$ (or $\mathrm{L}$ ) in Anderson's norms. Thus, a trait had to meet dual criteria of individual and normative evaluative extremity for each $S$.

Forty-eight experimental trait sets were generated from three replications of a 4 by 2 by 2 matrix (four set sizes of $\mathrm{H}$ or $\mathrm{L}$ traits with redundant or 
Table 1

Mean Person Impression Ratings as a Function of Number, Likableness, and Redundancy of Traits

\begin{tabular}{|c|c|c|c|c|c|}
\hline \multirow{2}{*}{$\begin{array}{c}\text { Trait } \\
\text { Likableness }\end{array}$} & \multirow{2}{*}{$\begin{array}{c}\text { Trait } \\
\text { Redundancy }\end{array}$} & \multicolumn{4}{|c|}{ Set Size } \\
\hline & & 2 & 3 & 4 & 6 \\
\hline $\mathbf{H}$ & $\begin{array}{l}\text { Redundant } \\
\text { Nonredundant }\end{array}$ & $\begin{array}{l}22.08 \\
23.32\end{array}$ & $\begin{array}{l}22.25 \\
24.75\end{array}$ & $\begin{array}{l}23.58 \\
26.05\end{array}$ & $\begin{array}{l}26.15 \\
28.45\end{array}$ \\
\hline $\mathbf{L}$ & $\begin{array}{l}\text { Redundant } \\
\text { Nonredundant }\end{array}$ & $\begin{array}{l}24.62 \\
23.85\end{array}$ & $\begin{array}{l}26.80 \\
25.87\end{array}$ & $\begin{array}{l}26.53 \\
27.73\end{array}$ & $\begin{array}{l}27.47 \\
29.45\end{array}$ \\
\hline
\end{tabular}

Table 2

$\overline{\mathbf{w}}$ Estimates as a Function of Number, Likableness, and Redundancy of Traits

\begin{tabular}{clccccc}
\hline \multirow{2}{*}{$\begin{array}{c}\text { Trait } \\
\text { Likableness }\end{array}$} & $\begin{array}{c}\text { Trait } \\
\text { Redundancy }\end{array}$ & 2 & 3 & 4 & 6 & $\overrightarrow{\mathrm{w}}$ \\
\cline { 3 - 7 } & Hedundant & .58 & .49 & .48 & .49 & .51 \\
& Nonredundant & .64 & .61 & .62 & .76 & .65 \\
L & Redundant & .70 & .74 & .66 & .61 & .68 \\
& Nonredundant & .66 & .68 & .75 & .88 & .74 \\
\hline
\end{tabular}

nonredundant traits within sets). Specifically, three $H$ and three $L$ words were selected which had obtained $\mathrm{H}$ or $\mathrm{L}$ ratings both normatively and from each individual in the study. Redundant traits (according to the matching procedure) were added to each word to form sets of Sizes 2, 3, 4, and 6. This procedure was repeated for nonredundant sets, except that traits added to the initial words were mutually nonredundant. Although no attempt was made to equate redundant and nonredundant sets for likableness, mean normative ratings of traits appearing in redundant and nonredundant sets were comparable $\overrightarrow{\mathrm{x}}_{\mathrm{L}}=.64, .68 ; \overline{\mathrm{x}}_{\mathrm{H}}=5.26$, 5.22 , respectively).

Twenty-four filler sets, composed of moderately likable or dislikable traits of varying set size, were added, and the resultant 72 sets were randomly ordered for presentation to $S s$ in individual sessions. Eight practice sets of mixed likableness and set size preceded the experimental and filler sets. A second replication, based on six new traits, was similarly constructed and presented to an independent sample of Ss. Each replication was administered to 10 male and 10 female Ss who were asked to rate, on a scale ranging from "dislike very much" $(-30)$ to "like very much" $(+30)$, their impression of the person described by each set. Ss were told that each trait was supplied by a different acquaintance of the stimulus person and that equal validity should be assumed for traits.

\section{RESULTS}

\section{Person Impression Ratings}

Mean person impression ratings were obtained for both replications of the 4 (set size) by 2 (trait likableness) by 2 (redundancy) design. An analysis of variance was performed on the data, and replications was found to be an insignificant factor. Accordingly, data for the two replications were combined and are presented in Table 1. For ease of calculation and presentation, the negative sign for $\mathrm{L}$ sets was reversed.

Immediately apparent is the fact that $L$ sets generally received more extreme ratings than did $\mathrm{H}$ sets, and an increase in number of traits in both sets led to more extreme evaluations. These observations are confirmed by significant ANOVA effects for traits $(\mathrm{F}=11.07, \mathrm{df}=1 / 38, \mathrm{p}<.01)$ and for set size $(F=9.92, \quad \mathrm{df}=3 / 114$, $p<.01)$. The first effect, while of some interest, is not relevant to the present hypothesis; the second finding establishes that a set size effect occurred.

Pertinent to the hypothesis, it may be observed that the magnitude of the set size effect is greater for nonredundant sets. Differences in ratings of nonredundant sets of 2 vs 6 traits were $5.13(\mathrm{H})$ and 5.60 (L), while redundant sets produced differences of 4.07 and 2.85 for $\mathrm{H}$ and $\mathrm{L}$ sets, respectively. This interaction between set size and redundancy was supported by ANOVA ( $F=2.89$, df $=3 / 114, \quad p<.05$ ). Thus, the hypothesis that redundancy would attenuate the set size effect was confirmed.

\section{Redundancy Estimates}

Trait pairs were considered redundant if, in the matching procedure, 20 or more Ss chose one trait as implying the other or they obtained a rating $>5.6$ on a 7 -point scale of likelihood of implication in the rating procedure. Multiplying number of agreements between procedures by 2 and dividing by the sum of redundant pairs in both procedures yielded a coefficient of agreement of .78 for $\mathrm{H}$ traits and .74 for $\mathrm{L}$ traits. Of 162 highly redundant $\mathrm{H}$ pairs, according to the matching criterion, 142 were also rated as redundant. The corresponding figures for $L$ pairs were 119 and 97, respectively. Further confirming the comparability of the two procedures, the mean ratings for $H$ and $L$ redundant pairs (matching criterion) were 5.9 and 5.7 , respectively, while the corresponding ratings for nonredundant pairs were 4.3 and 4.1 .

Only five trait pairs judged redundant by the matching criterion received a mean rating of less than 5.0 , while no nonredundant matched pairs achieved a rating greater than 5.1 . It was concluded that the two procedures yielded comparable results with respect to identifying highly redundant or implied trait pairs.

\section{DISCUSSION}

Redundancy, whether induced by use of synonyms, stimulus repetition, or trait implications, serves to attenuate the polarizing effect of increase in set size of univalent traits. This finding is contrary to predictions stemming from an additive model of information integration in impression formation (Anderson \& Fishbein, 1965; Feldman, 1968; Fishbein \& Hunter, 1964). Fishbein has suggested that weight of a trait in the combination process is proportional to S's belief that a trait is associated with a person. Redundancy is expected to accentuate this belief, leading to greater associated weight and, assuming additivity, a more polar rating. Employing repetition-induced redundancy, several studies have failed to support this prediction (Chalmers, 1964; Radtke, 1967; Schmidt, 1969). Feldman (1968) cautions, however, that complete redundancy does not provide a test of Fishbein's proposition because it adds a subtractive element, i.e., lack of variability is itself interpreted as a negative attribute. The present study, avoiding complete redundancy, nevertheless finds set-size-induced polarity to be attenuated, rather than enhanced, by redundancy.

A straightforward interpretation of the Redundancy by Set Size interaction suggests that the effect is mediated by the additional information conveyed by a specific trait as a function of its redundancy with other traits in the set. Schmidt (1969) has suggested that redundancy, by reducing the information contained in a set, reduces the weight of trait components in the combination process. Such reduction of weight can easily account for an attenuated set size effect if two major components of the person impression are taken into account: trait information and preevaluative dispositions. Anderson (1967) has provided a model of the impression formation process including both components:

$$
\mathbf{R}=\frac{\mathbf{k w A}+(1-\mathbf{w}) \mathrm{I}_{\mathbf{o}}}{\mathbf{k w}+(1-\mathbf{w})}
$$


where $R$ is the person impression, $k$ is the number of traits, $A$ is the scale value of a single trait, $w$ is the weight associated with the trait, and $I_{0}$ is the initial impression or preevaluative disposition. The model describes a process in which trait values and preevaluative dispositions are averaged, with weight of dispositions inversely related to trait weights in the averaging process.

Consider now the present experiment, where extreme values of A were employed ( $\mathrm{H}$ or $\mathrm{L}$ traits). Given that $I_{o}$ values were somewhat less extreme than $A$ values, it clearly follows that increases in polarity of response with increases in set size should be greatest when $w$ is maximized. That redundancy is associated with a less pronounced set size effect suggests that degree of redundancy affects the $w$ parameter. As a test of this proposition, w estimates were obtained for each cell in the 2 by 4 design by setting $I_{o}$ value at the scale midpoint and $A$ values at the appropriate endpoints, and solving for $w$ in $E q .1$. It should be noted that $w$ estimates are based on pooled data, since it seems more reasonable to assume a neutral $I_{0}$ for pooled Ss than for each $\mathrm{S}$ individually.

It is clear from Table 2 that, as expected, redundant sets receive less weight than nonredundant sets. Interestingly, $w$ appears to decrease with added set length in redundant sets. This trend would not be unexpected if it were assumed that internal redundancy was greater at the larger set size. Conversely, w does not decrease with added set size when nonredundant sets are considered; in fact, the w estimate was greatest at Set Size 6. This phenomenon was also noted by Anderson (1967), in sets relatively low in redundancy, and was ascribed to artifactual rating tendencies. i.e. scale end effects. Supporting this contention, the discrepant $w$ values of Set Size 6 were reduced with the introduction of anchor sets of Size 9 in a subsequent experiment (Anderson, 1967).

In conclusion, redundancy of stimulus traits serves to reduce the weight associated with traits in the impression formation process. Contrary to earlier theoretical formulations (Feldman, 1968; Fishbein \& Hunter, 1964), the addition of connotatively related information to a stimulus set increases reliance on stimulus information, and subsequently polarity of response, to a lesser degree than does the addition of connotatively unrelated information.

\section{REFERENCES}

ANDERSON, L. R., \& FISHBEIN, $M$. Prediction of attitude from the number strength. and evaluative aspect of beliefs about the attitude object: A comparison of summation and congruity theories. Journal of Personality \& Social Psychology, 1965, 2, 437-443.

ANDERSON, $N$. $H$. Averaging model analysis of set-size effect in impression formation. Journal of Experimental Psychology, 1967, 75, 158-165.

ANDERSON, N. H. Likableness ratings of 555 personality trait words. Journal of Personality \& Social Psychology, 1968, 9 272-279.

BRUNER, J. S., SHAPIRO, D., \& TAGUIRI, $R$. The meaning of traits in isolation and in combination. In $R$. Taguiri and L. Petrullo (Eds.), Person perception and interpersonal behavior. Stanford: Stanford University Press. 1958. Pp 277-288.

CHALMERS, D. Repetition of information and order of presentation in personality impression formation. Unpublished doctoral dissertation. State University of Iowa. 1964.

CRONBACH, L. J. Processes affecting scores on "understanding of others" and "assumed similarity." Psychological Bulletin, 1955, $52,177 \cdot 193$.

DUSTIN, D. S., \& BALDWIN, P. M Redundancy in impression formation.
Journal of Personality \& Social Psychology, 1966, 3, 500-506.

FELDMAN, $S$. What do you think of a cruel. wise man? The integrative response to a stimulus manifold. In R. P. Abelson. E. Aronson, W. J. McGuire, T. M. Newcomb. M. J. Rosenberg, and P. H. Tannenbaum (Eds.), Theories of cognitive consistency: A sourcebook. Chicago: Rand McNally, 1968 . Pp. 744.755.

FISHBEIN, M.. \& HUNTER, R. Summation versus balance in attitude organization and change. Journal of Abnormal \& Social Psychology, 1964, 69, 505-510.

HAKEL. M. D. Significance of implicit personality theories for personality research and theory. Proceedings, 77th Annual Convention, American Psychological Association. 1969. 403-404.

HALVERSON, C. F., JR. Interpersonal perception: Cognitive complexity and trait implication. Journal of Consulting \& Clinical Psychology, 1970, 34, 86-90.

HAYS, W. L. An approach to the study of trait implication and trait similarity. In $R$. Taguiri and L. Petrullo (Eds.), Person perception and interpersonal behatior. Stanford: Stanford University Press. 1955. Pp. 289-299.

KOLTUV. B. B. Some characteristics of intrajudge trait intercorrelations. Psychological Monographs, 1962, 76: (33, Whole No. 552).

NEWCOMB, T. An experiment designed to test the validity of a rating technique. Journal of Applied Psychology, 1931, 22. 279-289.

OSGOOD. C. E., SUCI, G. J., \& TANNENBAUM. P. H. The measurement of meaning. Urbana. IH: University of Illinois Press, 1957.

PASSINI, $r$. F.. \& NORMAN, W. T. A universal conception of personality structure? Joumal of Personality \& Social Psychology, 1966, 4, 44-49.

RADTKE, R. C. Repetition and redundancy of information in impression formation. Paper presented at the Meetings of Midwestem Psychological Association, Chicago, May 1967.

SCHMIDT, C. F. Personality impression formation as a function of relatedness of information and length of set. Journal of Personality \& Social Psychology, 1966 . 12, 6-11.

THORNDIKE, E. L. A constant error in psychological rating. Journal of Applied Psychology, 1920,4, 25-29. NOTE

1. Redundant and nonredundant traits for each of $40 \mathrm{H}$ and $45 \mathrm{~L}$ traits are available upon request. 